\title{
Differences in epidemiology of patients with preeclampsia between China and the US (Review)
}

\author{
PING SHI ${ }^{*}$, LEI ZHAO* , SHA YU, JUN ZHOU, JING LI, NING ZHANG, \\ BAOXIANG XING, XUENA CUI and SHENGMEI YANG
}

Department of Obstetrics, The Affiliated Hospital of Qingdao University, Qingdao, Shandong 266000, P.R. China

Received September 5, 2020; Accepted March 11, 2021

DOI: $10.3892 /$ etm.2021.10435

\begin{abstract}
Preeclampsia (PE) is a complex complication that occurs during pregnancy. Studies indicated that morbidity from PE exhibits marked variations among geographical areas. Disparities in the incidence of PE between China and the US may be due to differences in ethnicity and genetic susceptibility, maternal age, sexual culture, body mass index, diet, exercise, multiple pregnancies and educational background. These epidemiological differences may give rise to differences between the two countries in terms of diagnostic and therapeutic criteria for PE. PE may be largely attributed to susceptibility genes and lifestyles, such as diet, body mass index and cultural norms regarding sexual relationships. The epidemiologic differences of patients with PE between the two countries indicated that appropriate prevention plans for PE require to be developed according to local conditions.
\end{abstract}

\section{Contents}

1. Introduction

2. Pathological mechanisms of PE3.

3. Ethnic differences

4. Susceptibility genes

5. Age

6. Parity

7. Sexual culture

8. Obesity

9. Diet

10. Exercise

11. Educational background

12. Diagnosis

Correspondence to: Professor Ning Zhang, Department of Obstetrics, The Affiliated Hospital of Qingdao University, 16 Jiangsu Road, Qingdao, Shandong 266000, P.R. China

E-mail: qyfyzn@126.com

*Contributed equally

Key words: preeclampsia, China, United States
13. Individual therapy for PE

14. Limitations

15. Conclusions

\section{Introduction}

Preeclampsia (PE) is a common disorder associated with pregnancy, the symptoms of which are proteinuria and increased blood pressure that arises in previously normotensive females after 20 weeks of gestation and may influence multisystem function (1). Pre-eclampsia may cause issues in the brain, liver and kidneys, and aberrations in the clotting mechanism (2); it also represents a substantial risk for hypertension and associated cerebrovascular and cardiovascular disease (3). Worldwide, PE is one of the major causes of perinatal and maternal morbidity and mortality, particularly in middle- and low-income countries (4).

Worldwide, PE affects $2-8 \%$ of pregnancies. The incidence exhibits marked variations among countries and ethnicities (5). The present analysis suggested that the morbidity was higher in developing countries, particularly in Africa and Latin America $(6,7)$, and that Asians may be a low-risk population for PE (8). Several studies have reported similar observations and a low incidence of preeclampsia in the Chinese of Asia, in New Zealand and in Asian Americans in comparison to Native Americans, African Americans and Europeans (9,7).

According to published data, during the last decade, the morbidity of PE reported in the US was higher than that in China (9,7). From 2004 to 2016, there was a decline in morbidity due to PE in China, while during 1980-2016, a yearly increase in morbidity was observed in the US (Fig. 1 and Table I) (10-18). These observations were in discordance with the previously determined higher incidence of $\mathrm{PE}$ in developing countries and led us to explore the reasons for this difference.

\section{Pathological mechanisms of PE}

According to the different onset of the condition, PE may be divided into early-(<34 weeks) and late-onset (>34 weeks) PE (19). It is now recognized that early-onset and late-onset PE have different pathophysiologies, the former of which (also called placental PE), may be caused by the reduced 
maternal spiral arterial turnover in the first trimester and the latter (also called maternal PE) is related to reduced arterial turnover and increased placental perfusion (19). In early-onset PE, increased secretion of maternal serum angiogenic factor sFLT-1 and decreases in placental growth factor occur due to oxidative stress in the placenta (20). Fetal-derived trophoblast cells invade the maternal spiral artery and replace the endothelial cell layer in a normal pregnancy, which is called pseudo-angiogenesis or vascular mimicry process of vascular invasion, and trophoblasts differentiate from epithelial cells to endothelial cell phenotypes. However, in PE, trophoblasts cannot acquire the aggressive endothelial phenotypic characteristics, so the spiral arteries are insufficiently invasive, making them narrow and highly resistant (19). The changes of the above angiogenesis-related biomarkers are also used for monitoring and predicting PE (19). However, the above-mentioned highly recognized hypothesis does not appear to be directly related to the difference between the incidence and mortality of PE in China and the US. Subsequently, the potential risk factors were analyzed in the following context to help us prevent the occurrence of PE and even death due to PE.

\section{Ethnic differences}

A previous study indicated a variation in morbidity of $\mathrm{PE}$ among African Americans, Hispanics, Maori and Native Hawaiians (20). They then compared the rates of PE between Chinese living in Hawaii and Caucasians and the results indicated a higher risk of PE in the Chinese in Hawaii (20). However, the rates were also related to other factors, including the body mass index (BMI), maternal age, chronic hypertension, pregestational diabetes and smoking (20). Furthermore, a large retrospective cohort study from the UK observed that females of South Asia residing in the UK had an increased risk for PE compared with Caucasians (21). However, in another study performed from 2002 to 2011, in which 67,746 pregnant females participated, a lower prevalence of PE was observed in Chinese than in Caucasians (22). However, they did not distinguish between whether Caucasians were born or just lived in China. Furthermore, Chinese born in the US had a lower prevalence of PE than Chinese who lived in the US but were born in China (20). Besides the ethnic causes of the different rates of $\mathrm{PE}$, other factors also contributed to increased risks of PE $(20,22)$, which are summarized in Table II.

\section{Susceptibility genes}

In the pathogenesis of PE, a strong role for genetic factors is indicated by the ethnic groups' risk variations. Several genes have been determined to be associated with PE, such as inflammatory response, activation of endothelial cells and immunity $(11,22,23)$; certain genes are susceptibility genes, while others are protective genes.

Studies of the Chinese Han population have reported that the vitamin $D$ receptor gene with the $G$ allele of rs2228570, the IL-10-1082A/G and -819T/C, IL-27 rs153109 and rs17855750 variants, as well as $11 \beta$-hydroxysteroid dehydrogenase and killer-cell immunoglobulin-like receptor genetic variations are related to PE (24-26). Cyclooxygenase-1195A homozygosity and variant growth arrest-specific $6+1332 \mathrm{~T}$ allele were also indicated to correlate with a reduced PE risk in the Chinese Han population (27-29).

The analysis of a subset of placentae with early-onset and severe PE indicated a racial variation in NK2 homeobox 5 expression, being higher expressed in Caucasians than in African Americans (30).

Best et al (31) reported on the association between severe $\mathrm{PE}$ in a population of American Indians of Asian descent and a 3'UTR functional variant of the C-reactive protein (CRP) gene. They also indicated that the CRP variants rs876538 and rs3093068 were associated with PE in American Indians, additionally confirming a potential activity of CRP in PE (32).

\section{Age}

Various studies have explored the relationship of PE with advanced age of the mother $(33,34)$. The risk of PE rises in an exponential manner with maternal age, particularly in females above the age of 40 years (35). Over the last few decades, a delayed maternal age at childbirth has been observed, particularly in high-income countries (36). There was an increase in the mean age of first-time mothers from 24.9 in 2000 to 26.3 in 2014 in the US (37). This trend was also observed in China and may be due to enhanced emancipation of females in these countries. The advanced maternal age (AMA) in China and the US over recent years was then compared. The usual definition of AMA is any pregnancy occurring when the mother's age exceeds 35 years $(33,34)$. Fig. 2 indicates that more than 10 years later, the prevalence of AMA among patients with PE in China increased from 4.98 to $15.7 \%$ (35-42). By contrast, the prevalence of AMA in the USA decreased from 19.9 to $16.63 \%$ (43-45). Thus, as a rough estimate, AMA is more common in the US than in China.

\section{Parity}

The number of previous pregnancies with a gestational time of $>20$ weeks, irrespective of live birth or fetal death, is defined as parity. Several studies indicated that parous females experience an increased risk of PE compared with nulliparous females $(46,47)$. Multiparity as a risk factor for $\mathrm{PE}$ was identified through a case-control study (odds ratio, 3.6; 95\% CI: 2.6-5.0) (48). The shielding effect of multiparity remains to be fully elucidated and there may be a potential role of immune maladaptation and an immune reaction from the pregnant mother against paternal antigens resulting in PE (47). Furthermore, the risk of PE among multiparous females may possibly be lower due to desensitization after paternal antigen exposure in the placenta (49).

Most childbirths in China occur to nulliparous women due to the country's one-child policy. However, this policy was replaced by a universal two-child policy in October 2015 and the proportion of multipara began to increase and from $11.79 \%$ in $2005-2009$ to $35.84 \%$ in $2015-2016$ (50). However, the proportion of parturient females in China still exceeded that in the US (Fig. 3) (51,52).

\section{Sexual culture}

Further evidence demonstrates a role of the father in the onset of PE $(52,53)$. Multiparous females who change partners are 


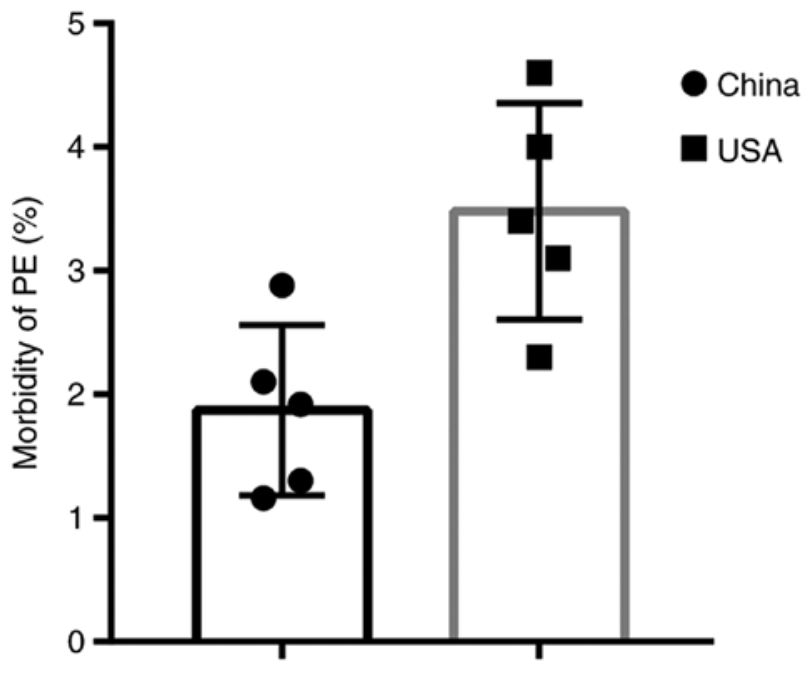

Figure 1. Morbidity of PE in China and the US. PE, preeclampsia.

frequently at an increased risk of PE in the following pregnancy in comparison to females who are multiparous and with the same partner (54). The PE risk increases in females who have no history of pregnancy and who changed partners; however, this risk decreases in females who already have a history of the condition (55). This is more or less universally accepted due to immunological tolerance.

Studies from the US indicated that $19 \%$ of females between the ages of 41 and 49 have more than one partner (49); however, due to the different cultures, there may be fewer partners for Chinese females than American females. Prior to conceiving, a stable sexual relationship is maintained by a majority of Chinese females for more than a year, usually with the same partner (11).

\section{Obesity}

In western countries, obesity with a BMI $\geq 30 \mathrm{~kg} / \mathrm{m}^{2}$ is a major health issue, which, in the 21 st century, is prevalent at a rate of $20 \%$ in the US (54). Compared with American pregnant females, obesity is less prevalent in Chinese pregnant females $(49,54-56)$. The percentage of obesity between Chinese and American populations was determined using the classification suggested by the World Health Organization (WHO). The population of patients with PE among pregnant women was categorized into four groups based on the BMI as follows: Underweight, BMI $<18.5$; normal, $18.5 \leq \mathrm{BMI}<25$; overweight, $25 \leq \mathrm{BMI}<30$; obese, $\mathrm{BMI} \geq 30$ (Fig. 4) $(57,58)$.

The risk of PE is increased in obesity $(59,60)$. Obesity and metabolic factors associated with obesity may bring about ischemia of the placenta and maternal vascular dysfunction to support the onset of PE (61).

The distribution of the BMI was different between Chinese and US Americans (Fig. 4), as obesity was more common in the US; however, the impact of a high BMI on PE in females from China was greater than that in Caucasians (46). This may be because of the higher body fat percentage in Chinese and the metabolic mechanism causing PE may be apparent even at a lower BMI in Chinese (62).
Table I. Incidence of preeclampsia in China and the US.

\begin{tabular}{lrcr}
\hline A, China & & & \\
\hline Years & Cases & Morbidity (\%) & (Refs.) \\
\hline $2004-2008$ & 13273 & 2.10 & $(10)$ \\
$2002-2011$ & 67746 & 1.92 & $(11)$ \\
2011 & 112386 & 2.88 & $(12)$ \\
$2005-2012$ & 1208559 & 1.16 & $(13)$ \\
$2013-2016$ & 21577 & 1.30 & $(14)$ \\
Average & & 1.34 & \\
\hline B, US & & & $($ Refs.) \\
\hline Years & & & $(10)$ \\
\hline 2007 & Cases & Morbidity (\%) & $(15)$ \\
$1980-2010$ & 1200000 & 4.00 & $(16)$ \\
$2002-2010$ & 36537061 & 2.30 & $(18)$ \\
$2007-2011$ & 2138012 & 3.10 & \\
$2007-2016$ & 1846535 & 4.60 & 2.49 \\
Average & & & \\
\hline
\end{tabular}

\section{Diet}

The dietary patterns have a relationship with the risk of PE (63). Vegetables and Mediterranean diets are more protective against $\mathrm{PE}$, while high meat/salt/fat diets increase the risk of PE $(64,65)$.

The characteristic diet pattern in the US includes a high intake of white bread, potatoes, margarine and mixed meat, which is high in salt and calories. Compared to Americans, the Chinese have a lower fat intake and their diet includes higher amounts of vegetables, grains and soy and comparatively lower amounts of sweets, alcohol and meat. The differences in their intake may be the cause of the variations in the incidence of PE and a different BMI distribution.

Nutritional factors were indicated to be related to PE. Particularly supplementation of calcium has a vital role in preventing PE among females with nutrient deficiency (66). The WHO recommends that pregnant females take calcium supplements, particularly in the populations at high risk and with a low-calcium diet (67), as compared to Americans, the Chinese consume fewer dairy products, which are high in calcium.

\section{Exercise}

Studies have indicated the beneficial effects of exercise performed by pregnant females in preventing complications, such as PE $(68,69)$. Exercising may prevent obesity, improve endothelial function, decrease oxidative stress and promote placental growth and vascular development (70).

Compared with American females, Chinese females are more sedentary throughout the whole pregnancy. This may be due to psychological fears specific to pregnancy such as 
Table II. Summary of factors contributing to increased risk of preeclampsia.

\begin{tabular}{lc}
\hline Risk factor & $\begin{array}{c}\text { Mean RR } \\
(95 \% \mathrm{CI})\end{array}$ \\
\hline $\begin{array}{l}\text { Genetic susceptibility } \\
\text { Lifestyle }\end{array}$ & $\begin{array}{c}\text { Increased }^{\mathrm{a}} \\
\text { Increased }^{\mathrm{a}}\end{array}$ \\
$\begin{array}{l}\text { Diet (high salt and calories, low calcium) } \\
\text { Physical activity (sedentary) }\end{array}$ & \\
Sexual culture (more than one partner) & \\
Low education & Increased $^{\mathrm{a}}$ \\
Previous preeclampsia & $7.19(5.85-8.83)$ \\
Insulin-dependent diabetes & $3.56(2.54-4.99)$ \\
Multiple pregnancies & $2.93(2.04-4.21)$ \\
Nulliparity & $2.91(1.28-6.61)$ \\
Family history of preeclampsia & $2.90(1.70-4.93)$ \\
Obesity & $2.47(1.66-3.67)$ \\
Age $>40$ years & $1.96(1.34-2.87)$ \\
Preexisting hypertension & $1.38(1.01-1.87)$ \\
\hline
\end{tabular}

$\mathrm{RR}$, risk ratio. ${ }^{\mathrm{a}} \mathrm{Risk}$ for preeclampsia increased, but by how much is unknown.

miscarriage and physical factors such as increased stomach size and fatigue. Furthermore, in China, the excessive diagnosis of threatened abortion and preterm labor is common and has led numerous pregnant females to opt for bed rest.

\section{Educational background}

Evidence indicates that less-educated females are more likely to suffer from hypertensive disorders of pregnancy than those who are highly educated (71). A similar distribution of educational background was revealed in China and in the US (Fig. 5) (72,73).

\section{Diagnosis}

PE is defined as new-onset hypertension with a blood pressure of $\geq 140 \mathrm{mmHg}$ (systolic) or $\geq 90 \mathrm{mmHg}$ (diastolic) beyond pregnancy of 20 weeks along with the occurrence of the following new-onset conditions, alone or combined (74): i) Proteinuria albumin: Creatinine $\geq 8 \mathrm{mg} / \mathrm{mmol}$ or urine protein/creatinine ratio $\geq 30 \mathrm{mg} / \mathrm{mmol}$ or on dipstick testing $\geq 1 \mathrm{~g} / \mathrm{l}[2+]$; ii) Other dysfunctions of maternal organs, such as involvement of liver or kidney, hematological or neurological issues or dysfunction of the uterus or the placenta including aberrant umbilical artery Doppler waveform analysis, and restriction of growth of the fetus or stillbirth.

The classical criteria for diagnosing PE are proteinuria and hypertension. From 2002, there has been an important change in the criteria of the American College of Obstetricians and Gynecologists (ACOG) definition of PE, i.e., confirmation of proteinuria is not required if evidence of other organ damage is present (75). In China, the guidelines for PE were in accordance with the AGOG criteria; however, the new guidelines

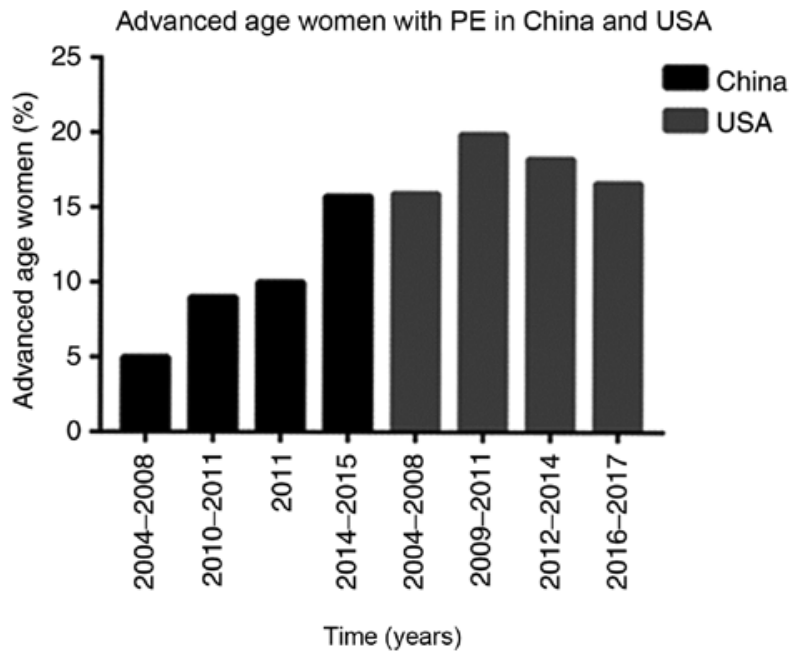

Figure 2. Percentage of patients with advanced maternal age in China and the US for over a decade. PE, preeclampsia. The $\mathrm{X}$ axis represents the years and references.

were implemented later in China than in the US and in certain areas of China, positive proteinuria is also required to diagnose PE (76). Indicators of organ damage such as headache, blurred vision and pain in the abdomen may be present and these observations may influence the reported incidence of PE in different countries (77).

\section{Individual therapy for $P E$}

The only effective way to eradicate PE is delivery, which increases the rate of preterm delivery. However, the modes of delivery vary between China and the US. In the US, the cesarean section rate was reported to be $62.1 \%$ in patients with severe PE (78), although a retrospective cohort study reported no obvious benefit from urgent delivery through cesarean on the outcomes of the mother and the infant among patients with severe PE (12). Furthermore, as per the ACOG recommendations, severe $\mathrm{PE}$ is not a complete contraindication to a labor induction clinical trial. However, in China, the rate of cesarean delivery among patients with severe PE was as high as $~ 88 \%$ (79).

To prevent the occurrence of $\mathrm{PE}$, various options were put forward, such as a low- $\mathrm{Na}^{+}$diet, diuretics, as well as supplementation of $\mathrm{Ca}^{2+}$ and Vitamin $\mathrm{C}$ and $\mathrm{E}$ (80). Among high-risk patients, administration of aspirin is advised at 11-14 weeks of gestation until 36 weeks due to the moderately reduced incidence of another type of PE, preterm PE (81). It is also worth mentioning that the approach proposed by the Aspirin for Evidence-based PE Prevention Trial for patients with preterm $\mathrm{PE}$, comprising a single intervention of daily aspirin, may be beneficial but not suitable for pregnant females with chronic hypertension; however, there was no evidence of heterogeneity in the effects of aspirin in subgroups defined by maternal characteristics and obstetric history (81). According to the above- mentioned differences between the two countries, therapeutic or prevention measures may be implemented based on individual characteristics, e.g. in view of the differences between the two countries, including a lower proportion of individuals with AMA, multipara and obese patients among 
A

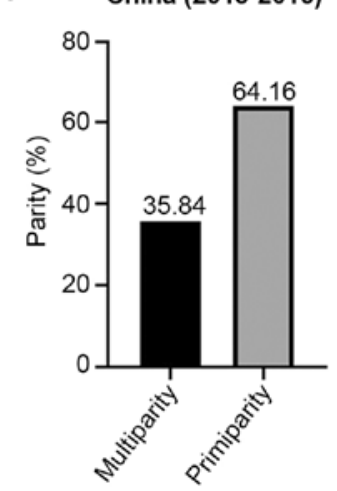

B

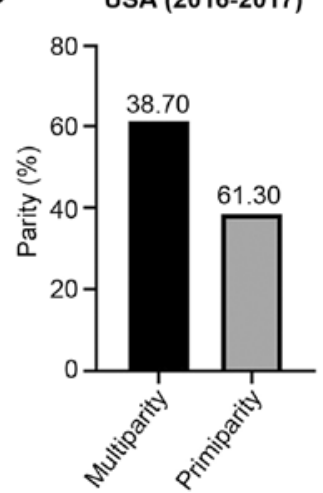

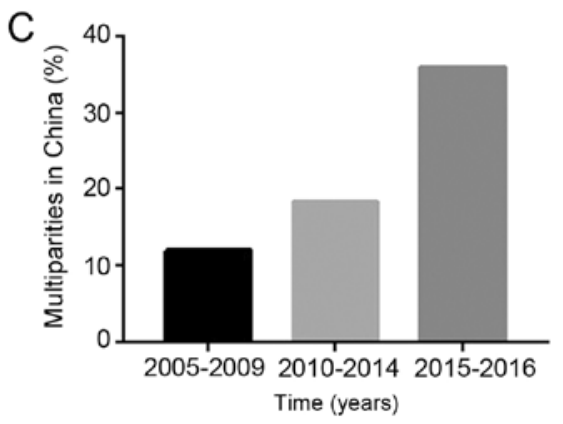

Figure 3. Proportion of multiparas in China and the US. The percentage of multipara and primipara with PE in (A) China from 2015 to 2016 , and (B) the US from 2016 to 2017. (C) Proportion of multipara with PE in China from 2005 to 2016. PE, preeclampsia.

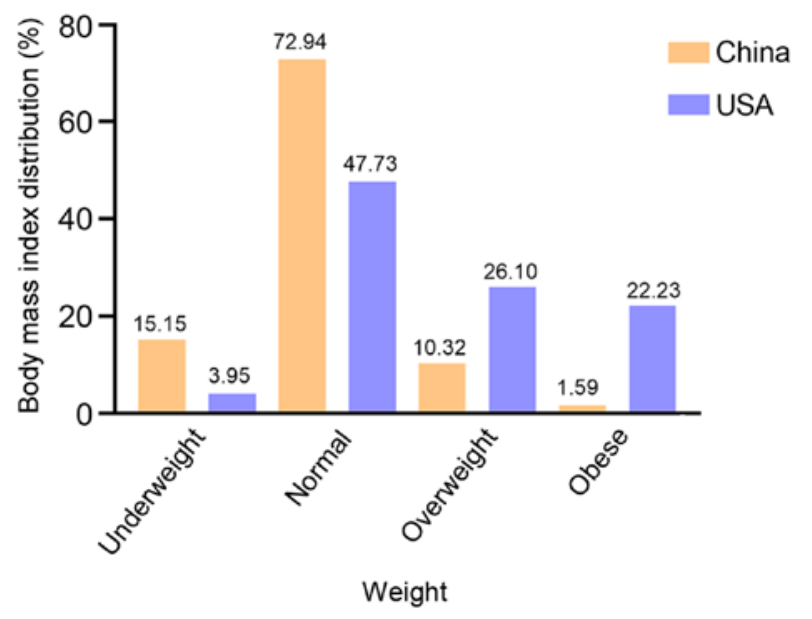

Figure 4. Body mass index distribution in Chinese and American patients with PE from 2014 to 2015. Compared with that in Chinese patients with PE, more obesity is observed in American patients with PE. PE, preeclampsia.

pregnant females in China compared with those in the US. For American pregnant females, it may be useful to prevent PE by lowering the age of pregnancy, reducing multipara, reducing weight appropriately and controlling weight gain during pregnancy. Furthermore, psychological stress may be a risk factor for pregnant females $(82,83)$, which may be related to educational background and work intensity (which may be reflected by their salary). The present results indicated that Chinese females have a similar educational level distribution to Americans. Hence, regardless of whether pregnant females are Chinese or American, attention should be paid to adjusting their pace of life to reduce the potential risk of mental stress.

Once PE becomes severe and develops into eclampsia, antispasmodic therapy is required, i.e. magnesium sulfate therapy in the short term $(<48 \mathrm{~h})$, which features a rapid onset of action, an easily available antidote (calcium gluconate), lack of sedation and low cost (84).

\section{Limitations}

Of note, the present study had certain limitations. First, China lacks a large-scale epidemiological investigation regarding the incidence of PE and most of the published data focused on
A

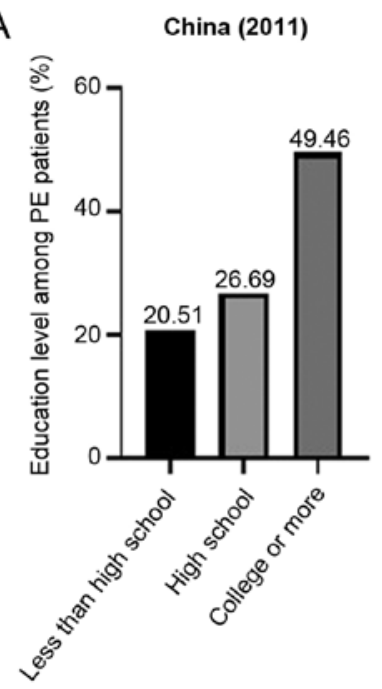

B

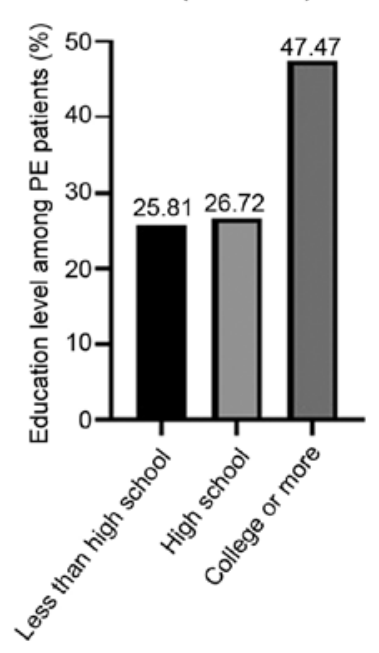

Figure 5. Level of education in (A) Chinese patients with PE in 2011 and (B) American patients with PE from 2007 to 2011. The educational background was nearly similar between Chinese and American patients with PE. PE, preeclampsia.

specific regions of China, which exhibit a wide geographical variation, such as smog/high air pollution. The occurrence of hypertensive disorders during pregnancy in central China was $1.23 \%$, while it was $7.44 \%$ in Northern China, which may relate to the economic and medical status of the region (71). Thus, the incidences presented in this review may not reflect the total incidence of PE in China. Furthermore, the risk factors between China and the US require to be compared in the same period. It is difficult to obtain data for the same period and with the development of the economy and medical technology, the current corresponding data may be different. Finally, the present study was a comparative review and not a meta-analysis, and therefore, it is important to consider the heterogeneity among the studies and the bias risk for the published selected articles.

\section{Conclusions}

The reasons for the variation in the incidence of PE between China and the US still remain to be fully elucidated. Certain 
risk factors such as age and BMI may be involved, while others may be less conclusive for the Chinese population. Therefore, further exhaustive research is still required. PE may be mostly attributed to gene polymorphisms and lifestyle factors such as diet, BMI and cultural norms pertaining to sexual relationships. These risk factors may give rise to epidemiological differences among countries and may suggest that prevention measures, such as exercise and weight and stress reduction, should be scheduled according to local conditions.

\section{Acknowledgements}

Not applicable.

\section{Funding}

No funding was received.

\section{Availability of data and materials}

Not applicable.

\section{Authors' contributions}

PS and LZ conceptualized the study and performed data analysis. NZ conceptualized the study, performed the literature search, collected and analyzed data and wrote the manuscript. SY, JZ and JL analyzed data. SY and BX performed the literature review and revised the manuscript. XC and SY performed the literature search. All authors have read and approved the final manuscript. Data authentication is not applicable.

\section{Ethics approval and consent to participate}

Not applicable.

\section{Patient consent for publication}

Not applicable.

\section{Competing interests}

The authors declare that they have no competing interests.

\section{References}

1. Rana S, Lemoine E, Granger JP and Karumanchi SA Preeclampsia: Pathophysiology, challenges, and perspectives. Circ Res 124: 1094-1112, 2019.

2. Jackson SP, Darbousset $R$ and Schoenwaelder SM Thromboinflammation: Challenges of therapeutically targeting coagulation and other host defense mechanisms. Blood 133: 906-918, 2019.

3. Coutinho T, Lamai O and Nerenberg K: Hypertensive disorders of pregnancy and cardiovascular diseases: Current knowledge and future directions. Curr Treat Options Cardiovasc Med 20 $56,2018$.

4. Poon LC, Shennan A, Hyett JA, Kapur A, Hadar E, Divakar H, McAuliffe F, da Silva Costa F, von Dadelszen P, McIntyre HD, et al: The international federation of gynecology and obstetrics (FIGO) initiative on pre-eclampsia: A pragmatic guide for first-trimester screening and prevention. Int J Gynaecol Obstet 145 (Suppl 1): S1-S33, 2019.
5. Dymara-Konopka W, Laskowska $\mathrm{M}$ and Oleszczuk $\mathrm{J}$ : Preeclampsia-current management and future approach. Curr Pharm Biotechnol 19: 786-796, 2018.

6. Osungbade KO and Ige OK: Public health perspectives of preeclampsia in developing countries: Implication for health system strengthening. J Pregnancy 2011: 481095, 2011.

7. American College of Obstetricians and Gy ETM_16253_261205_ Shi necologists: Gestational hypertension and preeclampsia: ACOG Practice Bulletin, number 222. Obstet Gynecol 135: e237-e260, 2020.

8. Fasanya HO, Hsiao CJ, Armstrong-Sylvester KR and Beal SG: A critical review on the use of race in understanding racial disparities in preeclampsia. J Appl Lab Med 6: 247-256, 2021.

9. ACOG Practice Bulletin No. 202 Summary: Gestational Hypertension and Preeclampsia. Obstet Gynecol 133: 1, 2019.

10. Umesawa M and Kobashi G: Epidemiology of hypertensive disorders in pregnancy: Prevalence, risk factors, predictors and prognosis. Hypertens Res 40: 213-220, 2017.

11. Xiao J, Shen F, Xue Q, Chen G, Zeng K, Stone P, Zhao M and Chen Q: Is ethnicity a risk factor for developing preeclampsia? An analysis of the prevalence of preeclampsia in China. J Hum Hypertens 28: 694-698, 2014.

12. Ye C, Ruan Y, Zou L, Li G, Li C, Chen Y, Jia C, Megson IL, Wei J and Zhang W: The 2011 survey on hypertensive disorders of pregnancy (HDP) in China: Prevalence, risk factors, complications, pregnancy and perinatal outcomes. PLoS One 9: e100180, 2014.

13. Wang Q, Zhang H, Liang Q, Knibbs LD, Ren M, Li C, Bao J, Wang S, He Y, Zhu L, et al: Effects of prenatal exposure to air pollution on preeclampsia in Shenzhen, China. Environ Pollut 237: 18-27, 2018.

14. Wang C, Lin L, Su R, Zhu W, Wei Y, Yan J, Feng H, Li B, Li S and Yang H: Hemoglobin levels during the first trimester of pregnancy are associated with the risk of gestational diabetes mellitus, pre-eclampsia and preterm birth in Chinese women: A retrospective study. BMC Pregnancy Childbirth 18: 263, 2018.

15. Ananth CV, Keyes KM and Wapner RJ: Pre-eclampsia rates in the United States, 1980-2010: Age-period-cohort analysis. BMJ 347: f6564, 2013

16. Abalos E, Cuesta C, Grosso AL, Chou D and Say L: Global and regional estimates of preeclampsia and eclampsia: A systematic review. Eur J Obstet Gynecol Reprod Biol 170: 1-7, 2013.

17. Marić I, Mayo JA, Druzin ML, Wong RJ, Winn VD, Stevenson DK and Shaw GM: Maternal height and risk of preeclampsia among race/ethnic groups. Am J Perinatol 36: 864-871, 2019.

18. Khandwala YS, Baker VL, Shaw GM, Stevenson DK, Lu Y and Eisenberg ML: Association of paternal age with perinatal outcomes between 2007 and 2016 in the United States: Population based cohort study. BMJ 363: k4372, 2018.

19. Armaly Z, Jadaon JE, Jabbour A and Abassi ZA: Preeclampsia: Novel mechanisms and potential therapeutic approaches. Front Physiol 9: 973, 2018.

20. Lou WZ, Jiang F, Hu J, Chen XX, Song YN, Zhou XY, Liu JT, Bian XM and Gao JS: Maternal serum angiogenic factor sFlt-1 to PlGF ratio in preeclampsia: A useful marker for differential diagnosis and prognosis evaluation in chinese women. Dis Markers 2019: 6270187, 2019.

21. Leon LJ, McCarthy FP, Direk K, Gonzalez-Izquierdo A, Prieto-Merino D, Casas JP and Chappell L: Preeclampsia and cardiovascular disease in a large UK pregnancy cohort of linked electronic health records: A CALIBER Study. Circulation 140: 1050-1060, 2019.

22. Khalil A, Rezende J, Akolekar R, Syngelaki A and Nicolaides KH: Maternal racial origin and adverse pregnancy outcome: A cohort study. Ultrasound Obstet Gynecol 41: 278-285, 2013.

23. Kang Q, Li W, Xiao J, Yu N, Fan L, Sha M, Ma S, Wu J and Chen S: Integrated analysis of multiple microarray studies to identify novel gene signatures in preeclampsia. Placenta 105: 104-118, 2021.

24. English FA, Kenny LC and McCarthy FP: Risk factors and effective management of preeclampsia. Integr Blood Press Control 8: 7-12, 2015.

25. Steegers EA, Von DP, Duvekot JJ and Pijnenborg R: Pre-eclampsia. Lancet 376: 631-644, 2010.

26. Rana S, Karumanchi SA and Lindheimer MD: Angiogenic factors in diagnosis, management, and research in preeclampsia. Hypertension 63: 198-202, 2014.

27. Jebbink J, Wolters A, Fernando F, Afink G, van der Post J and Ris-Stalpers C: Molecular genetics of preeclampsia and HELLP syndrome-A review. Biochim Biophys Acta 1822: 1960-1969, 2012. 
28. Liu B, Li Y, Yao Y, Li H, Liang H, Xin M, Wang L, Zhao L, Lin J and Liu S: Polymorphisms of the IL27 gene in a Chinese Han population complicated with pre-eclampsia. Sci Rep 6: 23029, 2016.

29. Ren R, Gao M, Fan P, Liu X, Liu R, Ma L, Chen Y, Liu Y and Bai $\mathrm{H}$ : Association study between-765G $>\mathrm{C}$ and $-1195 \mathrm{G}>\mathrm{A}$ functional polymorphisms in the cyclooxygenase 2 gene and risk of preeclampsia. Zhonghua Yi Xue Yi Chuan Xue Za Zhi 32 245-249, 2015 (In Chinese)

30. Rivers ER, Horton AJ, Hawk AF, Favre EG, Senf KM, Nietert PJ, Chang EY, Foley AC, Robinson CJ and Lee KH: Placental Nkx2-5 and target gene expression in early-onset and severe preeclampsia. Hypertens Pregnancy 33: 412-426, 2014.

31. Best LG, Saxena R, Anderson CM, Barnes MR, Hakonarson H, Falcon G, Martin C, Castillo BA, Karumanchi A, Keplin K, et al: Two variants of the $\mathrm{C}$-reactive protein gene are associated with risk of pre-eclampsia in an American Indian population. PLoS One 8: e71231, 2013

32. Best LG, Balakrishnan P, Cole SA, Haack K, Kocarnik JM, Pankratz N, Anderson MZ, Franceschini N, Howard BV, Lee ET, et al: Genetic analysis of hsCRP in American Indians: The strong heart family study. PLoS One 14: e0223574, 2019

33. Dior UP, Laufer N, Chill HH, Granovsky-Grisaru S, Yagel S, Yaffe $\mathrm{H}$ and Gielchinsky Y: Increased incidence of preeclampsia in mothers of advanced age conceiving by oocyte donation. Arch Gynecol Obstet 297: 1293-1299, 2018.

34. Fikadu K, F GM, Getahun F, Chufamo N and Misiker D: Determinants of pre-eclampsia among pregnant women attending perinatal care in hospitals of the Omo district, Southern Ethiopia J Clin Hypertens (Greenwich) 23: 153-162, 2020.

35. Lagerweij GR, Brouwers L, De Wit GA, Moons K, Benschop L, Maas A, Franx A, Wermer M, Roeters van Lennep JE, van Rijn BB and Koffijberg H: Impact of preventive screening and lifestyle interventions in women with a history of preeclampsia: A micro-simulation study. Eur J Prev Cardiol 27: 1389-1399, 2020.

36. Delnord M, Mortensen L, Hindori-Mohangoo AD, Blondel B, Gissler M, Kramer MR, Richards JL, Deb-Rinker P, Rouleau J, Morisaki N, et al: International variations in the gestational age distribution of births: An ecological study in 34 high-income countries. Eur J Public Health 28: 303-309, 2018.

37. Best LG, Saxena R, Anderson CM, Barnes MR, Hakonarson H, Falcon G, Martin C, Castillo BA, Karumanchi A, Keplin K, et al: Correction: Two Variants of the C-Reactive Protein Gene Are Associated with Risk of Pre-Eclampsia in an American Indian Population. PLOS One 8: e71231, 2013.

38. Marozio L, Picardo E, Filippini C, Mainolfi E, Berchialla P, Cavallo F, Tancredi A and Benedetto C: Maternal age over 40 years and pregnancy outcome: A hospital-based survey. J Matern Fetal Neonatal Med 32: 1602-1608, 2019.

39. Ogawa K, Urayama KY, Tanigaki S, Sago H, Sato S, Saito S and Morisaki N: Association between very advanced maternal age and adverse pregnancy outcomes: A cross sectional Japanese study. BMC Pregnancy Childbirth 17: 349, 2017.

40. Khalil A, Syngelaki A, Maiz N, Zinevich Y and Nicolaides KH Maternal age and adverse pregnancy outcome: A cohort study. Ultrasound Obstet Gynecol 42: 634-643, 2013.

41. Bréart G, Barros H, Wagener Y and Prati S: Characteristics of the childbearing population in Europe. Eur J Obstet Gynecol Reprod Biol 111 (Suppl 1): S45-S52, 2003.

42. Mathews TJ and Hamilton BE: Mean age of mothers is on the rise: United States, 2000-2014. NCHS Data Brief 232: 1-8, 2016.

43. Lu L, Qu Y, Tang J, Chen D, Chen D and Mu D: Risk factors associated with late preterm births in the underdeveloped region of China: A cohort study and systematic review. Taiwan J Obstet Gynecol 54: 647-653, 2015.

44. Laopaiboon M, Lumbiganon P, Intarut N, Mori R, Ganchimeg T, Vogel JP, Souza JP and Gülmezoglu AM; WHO Multicountry Survey on Maternal Newborn Health Research Network: Advanced maternal age and pregnancy outcomes: A multicountry assessment. BJOG 121 (Suppl 1): S49-S56, 2014

45. Liu X, Ruan Y, Liu Y and Zhang W: Relationship between maternal age and hypertensive disorders in pregnancy. Zhonghua Yi Xue Za Zhi 95: 19-22, 2015 (In Chinese).

46. Zhao RF, Zhou L and Zhang WY: Identifying appropriate pre-pregnancy body mass index classification to improve pregnancy outcomes in women of childbearing age in Beijing, China: A retrospective cohort study. Asia Pac J Clin Nutr 28: 567-576, 2019.
47. Sheen JJ, Huang Y, Andrikopoulou M, Wright JD, Goffman D, D'Alton ME and Friedman AM: Maternal age and preeclampsia outcomes during delivery hospitalizations. Am J Perinatol 37: 44-52, 2019.

48. deJongh BE, Paul DA, Hoffman M and Locke R: Effects of pre-pregnancy obesity, race/ethnicity and prematurity. Matern Child Health J 18: 511-517, 2014.

49. Liu B, Xu G, Sun Y, Du Y, Gao R, Snetselaar LG, Santillan MK and Bao W: Association between maternal pre-pregnancy obesity and preterm birth according to maternal age and race or ethnicity: A population-based study. Lancet Diabetes Endocrinol 7: 707-714, 2019.

50. Luo ZC, An N, Xu HR, Larante A, Audibert F and Fraser WD: The effects and mechanisms of primiparity on the risk of pre-eclampsia: A systematic review. Paediatr Perinat Epidemiol 21 (Suppl 1): S36-S45, 2007.

51. Hernandez-Diaz S, Toh S and Cnattingius S: Risk of pre-eclampsia in first and subsequent pregnancies: Prospective cohort study. BMJ 338: b2255, 2009.

52. Zheng Y, Ma C, Liu X, Wu S, Zhang W and Zhao S: Association between HLA-A gene polymorphism and early-onset preeclampsia in Chinese pregnant women early-onset. BMC Preg Childbirth 20: 656, 2020.

53. Kenny LC and Kell DB: Immunological tolerance, pregnancy, and preeclampsia: The roles of semen microbes and the father. Front Med 4: 239, 2017.

54. Tran PL, Robillard PY, Dumont C, Schweizer C, Omarjee A, Iacobelli S and Boukerrou M: Recurrent or first preeclampsia in multiparae: A case-control study of singleton pregnancies in Reunion Island. Eur J Obstet Gynecol Reprod Biol 240: 80-86, 2019.

55. Xie M, Lao TT, Du M, Sun Q, Qu Z, Ma J, Song X, Wang M $\mathrm{Xu}$ D and Ma R: Risk for Cesarean section in women of advanced maternal age under the changed reproductive policy in China: A cohort study in a tertiary hospital in southwestern China. J Obstet Gynaecol Res 45: 1866-1875, 2019.

56. Kenny LC and Kell DB: Immunological tolerance, pregnancy and pre-eclampsia: The roles of semen microbes and the father. Front Med (Lausanne) 4: 239, 2017.

57. Broughton Pipkin F: Risk factors for preeclampsia. N Engl J Med 344: 925-926, 2001.

58. Weir CB and Jan A: BMI Classification Percentile And Cut Off Points. In: Stat Pearls Publishing Copyright ${ }^{\oplus}$ 2020. Stat Pearls Publishing LLC, Treasure Island, FL, 2020.

59. Lopez-Jaramillo P, Barajas J, Rueda-Quijano SM, Lopez-Lopez C and Felix C: Obesity and Preeclampsia: Common pathophysiological mechanisms. Front Physiol 9: 1838, 2018.

60. He XJ, Dai RX and Hu CL: Maternal prepregnancy overweight and obesity and the risk of preeclampsia: A meta-analysis of cohort studies. Obesity Res Clin Pract 14: 27-33, 2020

61. Ives CW, Sinkey R, Rajapreyar I, Tita ATN and Oparil S: Preeclampsia-pathophysiology and clinical presentations: JACC state-of-the-art review. J Am Coll Cardiol 76: 1690-1702, 2020.

62. Ratnasiri AWG, Lee HC, Lakshminrusimha S, Parry SS, Arief VN, DeLacy IH, Yang JS, DiLibero RJ, Logan J and Basford KE: Trends in maternal prepregnancy body mass index (BMI) and its association with birth and maternal outcomes in California, 2007-2016: A retrospective cohort study. PLoS One 14: e0222458, 2019.

63. Cao Y, Liu Y, Zhao X, Duan D, Dou W, Fu W, Chen H, Bo Y, Qiu Y, Chen G and Lyu Q: Adherence to a dietary approaches to stop hypertension (DASH)-style diet in relation to preeclampsia: A case-control study. Sci Rep 10: 9078, 2020.

64. Dasinger JH, Abais-Battad JM and Mattson DL: Influences of environmental factors during preeclampsia. Am J Physiol 319: R26-R32, 2020.

65. Mi B, Wen X, Li S, Liu D, Lei F, Liu R, Shen Y, Chen Y, Zeng L, Liu X, et al: Vegetable dietary pattern associated with low risk of preeclampsia possibly through reducing proteinuria. Preg Hypertens 16: 131-138, 2019.

66. Hofmeyr GJ, Betrán AP, Singata-Madliki M, Cormick G, Munjanja SP, Fawcus S, Mose S, Hall D, Ciganda A, Seuc AH, et al: Prepregnancy and early pregnancy calcium supplementation among women at high risk of pre-eclampsia: A multicentre, double-blind, randomised, placebo-controlled trial. Lancet 393: 330-339, 2019.

67. Dekker GA: Risk factors for preeclampsia. Clin Obstet Gynecol 42: 422-435, 1999.

68. Ikem E, Halldorsson TI, Birgisdóttir BE, Rasmussen MA, Olsen SF and Maslova E: Dietary patterns and the risk of pregnancy-associated hypertension in the Danish National Birth Cohort: A prospective longitudinal study. BJOG 126: 663-667, 2019. 
69. Syngelaki A, Sequeira Campos M, Roberge S, Andrade W and Nicolaides KH: Diet and exercise for preeclampsia prevention in overweight and obese pregnant women: Systematic review and meta-analysis. J Matern Fetal Neonatal Med 32: 3495-3501, 2019.

70. Ersbøll AS, Bojer AS, Hauge MG, Johansen M, Damm P, Gustafsson F and Vejlstrup NG: Long-term cardiac function after peripartum cardiomyopathy and preeclampsia: A danish nationwide, clinical follow-up study using maximal exercise testing and cardiac magnetic resonance imaging. J Am Heart Assoc 7: e008991, 2018.

71. Cordero C, Windham GC, Schieve LA, Fallin MD, Croen LA, Siega-Riz AM, Engel SM, Herring AH, Stuebe AM, Vladutiu CJ and Daniels JL: Maternal diabetes and hypertensive disorders in association with autism spectrum disorder. Autism Res 12: 967-975, 2019.

72. Bahmanpour S: Guideline: Calcium Supplementation in Pregnant Women. Geneva Switzerland Who 6: 61-92, 2013.

73. Awad MA, Hasanin ME, Taha MM and Gabr AA: Effect of stretching exercises versus autogenic training on preeclampsia. J Exerc Rehabil 15: 109-113, 2019.

74. Skow RJ, King EC, Steinback CD and Davenport MH: The influence of prenatal exercise and pre-eclampsia on maternal vascular function. Clin Sci 131: 2223-2240, 2017.

75. Genest DS, Falcao S, Gutkowska J and Lavoie JL: Impact of exercise training on preeclampsia potential preventive mechanisms. Hypertension 60: 1104-1109, 2012.

76. Qi HB: Diagnosis and management of preeclampsia: Need for standardization. Chin J Perinatal Med 18: 411-413, 2015 (In Chinese)

77. Gu WR and Li XT: Intervention and management of preeclampsia. Chin J Appl Gynecol Obstet 36: 29-32, 2020 (In Chinese).
78. Karlsen S, Say L, Souza JP,Hogue CJ, Calles DL, Gülmezoglu AM and Raine R: The relationship between maternal education and mortality among women giving birth in health care institutions: Analysis of the cross sectional WHO Global Survey on Maternal and Perinatal Health. BMC Public Health 11: 606, 2011

79. Jim B and Karumanchi SA: Preeclampsia: Pathogenesis, prevention, and long-term complications. Semin Nephrol 37: 386-397, 2017.

80. Atallah A, Lecarpentier E, Goffinet F, Doret-Dion M, Gaucherand P and Tsatsaris V: Aspirin for prevention of preeclampsia. Drugs 77: 1819-1831, 2017.

81. Poon LC, Wright D, Rolnik DL, Syngelaki A, Delgado JL, Tsokaki T, Leipold G, Akolekar R, Shearing S, De Stefani L, et al: Aspirin for Evidence-Based Preeclampsia Prevention trial: Effect of aspirin in prevention of preterm preeclampsia in subgroups of women according to their characteristics and medical and obstetrical history. Am J Obstet Gynecol 217: 585.e1-585.e5, 2017.

82. Zhang S, Ding Z, Liu H, Chen Z, Wu J, Zhang Y and Yu Y: Association between mental stress and gestational hypertension/preeclampsia: A meta-analysis. Obstet Gynecol Surv 68: 825-834, 2013.

83. Korish AA: Magnesium sulfate therapy of preeclampsia: An old tool with new mechanism of action and prospect in management and prophylaxis. Hypertens Res 35: 1005-1011, 2012.

84. Marić I, Mayo JA, Druzin ML, Druzin M, Wong RJ, Winn VD, Stevenson DK and Shaw GM: Maternal height and risk of preeclampsia among race/ethnic groups. Am J Perinatol 36: 864-871, 2019.

(7) $\Theta$ This work is licensed under a Creative Commons Attribution-NonCommercial-NoDerivatives 4.0 International (CC BY-NC-ND 4.0) License. 